\title{
EFFECT OF COOKING METHODS ON AMINO ACIDS COMPOSITION OF CHICKEN MEAT
}

\section{ВЛИЯНИЕ СПОСОБОВ ПРИГОТОВЛЕНИЯ НА АМИНОКИСЛОТНЫЙ СОСТАВ МЯСА ПТИЦЫ}

Thanaa Shehab

Al-Fuart University, Deir Ezzor, Syria

Ключевые слова: методы приготовления, микроволновая обработка, мясо птицьь, аминокислотьы.

\begin{abstract}
Аннотация
Мясо птиць является важной составляющей сирийской диеты. Увеличение производства мяса птицы, его широкое использование в заведениях общественного питания диктует необходимость наличия подробной информации о качестве и содержании питательных веществ в нем. Установлено, что кулинарные методы обработки по-разному воздействуют на наличие питательных веществ в мясе птицы. Таким образом, данное исследование проводилось с иелью оиенить воздействие приготовления в микроволновой печи на состав аминокислот мяса (филе и бедро) иььплят-бройлеров по сравнению с традиционными методами кулинарной обработки: отвариванием, приготовлением под давлением и поджариванием.
\end{abstract}

\section{Введение}

В Сирии мясо птицы занимает лидирующее положению по производству и потреблению среди всех других видов мяса птицы. Оно стало вторым по популярности потребляемым мясом и, скорее всего, сохранит свои позиции. Данный вид сырья является хорошим источником белка и многих нутриентов, и содержит относительно небольшое количество жира, особенно, при условии его использования без кожи. Мясо цыплят-бройлеров также характеризуется возможностью использования для разных целей при планировании меню, легкостью приготовления, стабильным качеством и наличием широкого ассортимента предварительно упакованных, брендовых, сырых и готовых к употреблению и подачи продуктов.

Во многих странах объемы пищевых продуктов, подвергнутых кулинарной обработки с использованием микроволновых воздействий, увеличиваются год от года из-за удобства и сокращения продолжительности процесса. Улучшение конструкции микроволновых печей высокой мощности обеспечивает быстрые и экономичные методы производства пищевых продуктов с высокими органолептическими свойствами и пищевой ценностью [13].

В пищевой промышленности микроволновая обработка применяется для пастеризации упакованных продуктов, стерилизации, для отепления замороженных продуктов, предварительной обработки продуктов из мяса птицы и снеков. Использование микро-
Keywords: cooking methods, microwave, chicken, amino acids.

\section{Abstract}

Chicken meat is an important item in the Syrian diet. The increasing production of chickens and their potential in restaurants and food service operation implies the need for more detailed information regarding their quality and nutrient retention. Cooking methods have different effects on the values of nutrients of chicken. Therefore, this study was carried out to evaluate the effect of microwave cooking in amino acids composition of chicken meat (breast othigh) as compared with some conventional methods, i.e. boiling, pressure and roasting.

\section{Introduction}

In Syria chicken occupies a major place in production and consumption among poultry. It has become the second most popular meat eaten and is most likely to maintain this position. Chicken meat is a good source of protein and many nutrients, and is relatively low in fat, especially if the skin is removed. Chicken meat is also characterized by versatility in menu planning, ease of preparation, consistent quality, and the availability of wide range of pre-packaged, branded, raw and ready to eat and serve products.

In many countries microwave cooking and processing have increased over the years because of its convenience and time saving. Improvements in the design of high-powered microwave ovens offer rapid and economic methods for manufacturing food products of high organoleptic properties and nutritional value [13].

In the food industry microwaves are used for pasteurization of packaged products, for sterilization, tempering of frozen foods, precooking of poultry products and snack food also. Microwave use becomes of great importance because of its extensive utilization at home for cooking, thawing and re-heating. It is used also in research due for nutrient retention in processed food [11]. 
волн приобретает большое значение из-за широкого применения в домашних условиях для приготовления, размораживания и разогрева. Они также используются в исследованиях для обеспечения сохранения нутриентов в переработанных пищевых продуктах [11].

Alfaia et al. [3] установили, что время нагревания, температура, метод приготовления и состав мышц являются важными переменными, которые могут оказывать влияние на конечные желательные характеристики мяса. Хотя изменения в мясе, вызванные термообработкой, изучаются в течение многих лет и широко обсуждаются (Tornberg, [14]), только в небольшом количестве работ сообщается о влиянии различных условий термообработки на содержание аминокислот и минеральных веществ (Wilkinson, et al., [17]). Кроме того, состав нутриентов термообработанного мяса в доступных базах данных довольно ограничен.

Happich et al. [7] сообщили о том, что качество заменимых аминокислот варьирует, и что эти вариации в основном объясняются различиями в глицине, гидроксилизине и гидроксипролине. Общие заменимые аминокислоты поставляют азот для синтеза в организме каких-либо заменимых аминокислот, которых может не хватать. Кроме того, Barr et al. [5] and Hamm [6] сообщили о том, что количество валина, лейцина, изолейцина и гистидина было больше в мясе куриной грудке, в то время как мясо бедра имело больше глицина, гидроксипролина, гидроксилизина, треонина и серина.

Результаты исследований указывают на то, что район выращивания и соответствующие практики менеджмента, по всей вероятности, оказывают влияние на содержание почти половины аминокислот в мясе. Помимо этого, установлено, что мясо от самцов содержало больше гидроксипролина по сравнению с мясом самок.

Abd El-Wahed [2] сообщает, что свежее мясо грудок и бедер содержит те же индивидуальные аминокислоты с небольшими вариациями в их количестве. Кроме того, Ibrahim and Shams El-Din [8] сообщают, что содержание аминокислот в мясе куриных грудок включает лизин 11,12 ; треонин 4,24 ; валин 5,22 ; изолейцин 5,40 ; гистидин 4,11; аргинин 5,88; аспарагиновую кислоту 8,88; глутаминовую кислоту 4,92; серин 4,05; пролин 4,07; глицин 4,11; аланин 5,98; тирозин 3,77 (г/100 г белка).

Сообщается, что лизин теряется в результате реакции окисления жира при температурах ниже $100^{\circ} \mathrm{C}$, в то время как при высоких температурах (т.е., 115$130^{\circ} \mathrm{C}$ ), потери не зависели от присутствия жира (Lea et al.[9]). Однако, Macy et al. [10] установили, что концентрации большинства свободных аминокислот увеличивались при термообработке порционных кусков для жарки до достижении температуры в центре куска $77^{\circ} \mathrm{C}$ за исключением треонина, серина, глутаминовой кислоты, гистидина и аргинина. Общее увеличение содержания аминокислот объясняется гидролизом
Alfaia et al. [3] found the heating time, temperature, cooking method and muscle composition to be the important variables, which may influence the final desirable characteristics of meat. Although meat changes induced by cooking have been studied for many years and extensively discussed (Tornberg,[14]), only few reports have specifically dealt with the influence of different cooking conditions on the amino acid and mineral contents (Wilkinson, et al., [17]). Moreover, the nutrient composition of cooked meat available in food composition databases is quiet limited.

Happich et al. [7] reported that the quantity of nonessential amino acids varies, and that this variation is largely accounted for by the difference in glycine, hydroxylsine and hydroxyproline. Total non-essential amino acids supply nitrogen for the synthesis in the body of any of the nonessential amino acids, which may be lacking. Besides, Barr et al. [5] and Hamm [6] reported that amounts of valine, leucine, isoleucine and histidine were great in breast meat, whereas, thigh meat had more glycine, hydroxyproline, hydroxylysine, threonine and serine.

Furthermore, results indicated that area of production and related management practices appeared to influence the concentration of about half of the amino acids. Moreover, meat from males contained more hydroxyporline than that from females.

Abd El-Wahed [2] reported that the fresh breast and leg meat contained the same individual amino acids with a slight variation in their amount. Besides, Ibrahim and Shams El-Din [8] reported that amino acids content of breast chicken meat contained lysine 11,12, threonine 4,24, valine 5,22, isoleucine 5,40, histidine 4,11, arginine 5,88, aspartic acid 8,88, glutamic acid 4,92, serine 4,05, proline 4,07 , glycine 4,11 , alanine 5,98 , tyrosine 3,77 (g/100g protein).

It was reported that lysine was lost by reaction with autoxidizing fat at temperatures below $100^{\circ} \mathrm{C}$, while at high temperatures(i.e. $115-130^{\circ} \mathrm{C}$ ) the loss was apparently independent of the presence of fat (Lea et al.[9]). However, Macy et al. [10] found that most free amino acids increased in concentration during cooking of roasts to an internal temperature of $77^{\circ} \mathrm{C}$ with the exception of threonine, serine, glutamic acids, histidine and arginine. They attributed this general increase in amino acids content to hydrolysis of protein by proteolyttic enzymes. Most free amino acids decreased during heating, when isolated from the tissue by dialysis. Besides, heat treatment (at $163^{\circ} \mathrm{C}$ ) was found to 
белка протеолитическими ферментами, а количество большинства свободных аминокислот при жарке снижается. Помимо этого, было установлено, что термообработка (при $163^{\circ} \mathrm{C}$ ) увеличивает концентрации серина, глутаминовой кислоты и валина, изолейцина, лейцина, тирозина, фенилаланина и аргинина в мясе (Usborn et al., [15]).

Кроме того, Натm [6] провел анализ образцов мяса грудок и бедер от бройлеров, выращенных и переработанных в четырех районах США на их аминокислотный состав. В пересчете на процентное содержание белка количество валина, лейцина, изолейцина и гистидина было достоверно больше в грудках, а глицина, гидроксипролина, гидроксилизина, треонина и серина было больше в мясе бедер. В то же время, Moawad, [12] сообщил, что общее количество аминокислот, общее количество незаменимых и заменимых аминокислот в термообработанной говядине было 86,34; 33,01 и 53,33 г/16 г N, соответственно.

В этой связи, целью данной работы было изучение влияния различных способов обработки (варка, обработка давлением, обжарка и микроволновая обработка) на аминокислотный состав мяса бройлеров (бедер и грудок).

\section{Материалы и методы}

Использованные в данном исследовании бройлеры были получены на местных рынках Дамаска. Их вес был в диапазоне между (1100-1400 г) и средний возраст -8 недель.

Цыплята были забиты, вручную ощипаны, очищены и вымыты водой. Крылья, шеи и головы были удалены вручную. Тушки были нарезаны на четыре части (два куска грудок и два куска бедер). Части кур (бедра и грудки) были термообработаны следующими методами:

1 - варка: части цыплят (бедра и грудки) были обработаны в кипящей воде в количестве достаточном для того, чтобы покрыть их в соотношении 2:1 (вода: цыплята) в течение 30 мин.

2 - варка под давлением: части кур цыплят (бедра и грудки) были помещены в кастрюлю-скороварку и термообработаны в течение 20 мин.

3 - поджаривание: части цыплят (бедра и грудки) были поджарены в предварительно нагретой обычной электропечи до $180^{\circ} \mathrm{C}$ в течение нескольких минут.

4 - термообработка в микроволновой печи: два бедра и две грудки были помещены на блюдо для запекания и термообработаны в микроволновой печи при высоком уровне мощности в течение 20 мин. - 10 мин. с одной стороны и 10 мин. с другой стороны.

Влагу, золу, общие липиды и общий белок определяли в соответствии с методами, рекомендованными A.O.A.C.[4]. Все определения проводили в трехкратной повторности и регистрировали средние значения. raise the concentration of serine, glutamic acid and valine, isoleucine, leucine, tyrosine, phenylalanine and arginine in meat (Usborn et al., [15]).

In addition, Hamm [6] analyzed broiler breast and thigh meat samples from birds grown and processed in four locations of the U.S. for their amino acid composition. On percent protein basis amounts of valine, leucine, isoleucine and histidine were significantly greater in breast and glycine, hydroxyproline, hydroxylysine, threonine and serine were greater in thigh meats. Meanwhile, Moawad, [12] reported that the total amino acids, total essential amino acids and non-essential amino acids for fresh cooked beef meat were found to be $86,34,33,01$ and $53,33 \mathrm{~g} / 16 \mathrm{~g} \mathrm{~N}$ respectively.

Therefore, the aim of this research was to study the effect of different cooking methods (boiling, pressure-cooking, roasting and microwave) on amino acids composition of chicken meat (thighs and breasts).

\section{Materials and methods}

The broilers used in this study were obtained from the local Damascus markets. Their weight ranged between (1100-1400 g) and the average age 8 weeks.

Chickens were slaughtered, plucked by hand, cleaned and washed with water. The wings, neck and heads were removed by hand. The carcasses were then cut into four parts (two breast pieces and two thighs). Chicken parts (thighs and breasts) were cooked by the following methods:

1 - Boiling: Chicken parts (thighs and breasts) were cooked in sufficient amounts of boiling water to cover it at ratio 2:1 (water: chicken) for 30 minutes.

2 - Pressure-cooking: Chicken parts (thighs and breasts) were placed in a pressure cooker and cooked for 20 minutes.

3 - Roasting: Chicken parts (thighs and breasts) were roasted by using a preheated conventional electric oven to $180^{\circ} \mathrm{C}$ for minutes.

4 - Cooking by microwave oven: Two thighs and two breasts were placed in a baking dish and cooked in Microwave oven on a high power level for 20 minutes, 10 minutes on one side and 10 minutes on the other.

Moisture, ash, total lipids and total protein were determined according to the methods recommended by the A.O.A.C.[4]. All determination was performed in triplicates and the mean values were reported.

Amino acids were determined at the laboratories of agriculture faculty. High performance Amino Acid Analyzer was used as described by Winder and Eggum, [16]. Acid hydrolysis was performed in sealed ampoules for the de- 
Аминокислоты определяли в лабораториях на сельскохозяйственном предприятии. Был использован высокоэффективный аминокислотный анализатор, как описано Winder and Eggum, [16]. Кислотный гидролиз был проведен в герметичных ампулах для определения всех аминокислот помимо метионина, цистеина и триптофана. Метионин был определен в гидролизатах окисленной пробы как метионин сульфон, цистеин как цистеиновая кислота.

Образцы были взвешены (20-30 мг) в ампулах и было добавлено 5 мл $6 \mathrm{~N} \mathrm{HCl}$. Ампулы затем были запаяны под вакуумом. Образцы затем нагревали в печи при $110^{\circ} \mathrm{C}$ в течение 24 ч. Запаянные ампулы были открыты и соляная кислота была выпарена под вакуумом. Натрий-цитратный буфер (рH 2,2) был использован для растворения образцов и для разведения их до требуемого объема. Для аминокислотного анализа был использован фильтрованный гидролизат в высокоэффективном аминокислотном анализаторе (был введен образец объемом $50 \mu$ ).

Представленные в таблицах данные являются средними значениями трех проведенных одновременно исследований. Статистический анализ был основан на однофакторном дисперсионном анализе; были сформированы гомогенные группы в соответствии с критерием Дункана для $\mathrm{P}<0,05$. Данные были статистически проанализированы, используя STATISTICA (программную систему для анализа данных).

\section{Результаты и обсуждение}

Образцы мяса куриных грудок и бедер были проанализированы на содержание в них влаги, белка, жира и золы. Полученные результаты представлены в таблице 1.

Анализ данных в таблицы 1 показывает, что содержание влаги в мясе куриных грудок было приблизительно на 1\% выше по сравнению с образцами мяса куриных бедер. Количество влаги в грудках и бедрах составило 74,15 и 73,07\%, соответственно.

Как и ожидалось, процент жира в мясе куриных грудок был значительно ниже по сравнению с мясом бедер $(\mathrm{P}<0,05)$. Среднее содержание жира куриных грудках и бедрах было 12,18 и 21,65\% (в пересчёте на сухую массу), соответственно.

Как видно из таблицы 1 мясо куриных грудок и бедер содержало 3,94 и 3,72\% золы (в пересчёте на сухую массу), соответственно.

Аминокислотный состав мяса куриных грудок и бедер показан в таблице 2. Из результатов, представленных в таблице, видно, что мясо куриных грудок и бедер содержит те же аминокислоты с небольшими различиями в их количестве $(\mathrm{P}>0,05)$. Схожие результаты были установлены Abd El-Wahed [2]. Peзультаты приведенные в таблице 2, показывают, что мясо куриных грудок содержало большее количество серина, гистидина, аргинина, треонина, валина, ме- termination of all amino acids other than methionine, cysteine and tryptophan. In the oxidized hydrolysis, methionine was determined as methionine sulphone and cysteine was detected in the form of cysteine acid.

Samples were weighed (20-30 mg) in the ampoules and $5 \mathrm{mls}$. of $6 \mathrm{~N} \mathrm{HCl}$ were added. The ampoules were then sealed under vacuum. Samples were then heated in an oven at $110^{\circ} \mathrm{C}$ for 24 hours. The sealed ampoules were then opened and the hydrochloric acid was evaporated under vacuum. Sodium citrate buffer $(\mathrm{pH} 2,2)$ was used to dissolve the samples and to dilute it to the required volume. The filtrated hydrolysate was used for the amino acid analysis in High Performance Amino Acid Analyzer (a sample of $50 \mu \mathrm{L}$-volume was injected).

Numbers presented in the tables are the mean values of three concurrent iterations. Statistical analysis was based on the one-way analysis of variance; homogeneous groups were formed according to the Duncan test for $\mathrm{P}<0,05$. The data were statistically analysed using STATISTICA (data analysis software system).

\section{Results and discussion}

Fresh raw chicken breast and thigh meat samples were analyzed for their moisture, protein, fat, and ash. The obtained results are, hereafter shown in Table 1.

The analysis data in Table 1 indicated that the moisture content of chicken breast samples was approximately $1,0 \%$ higher than thigh meat samples. The percentages of moisture of fresh raw breast and thigh meat were 74,15 and $73,07 \%$, respectively.

As expected, the percentage of fat in chicken breast meat was significantly lower than that in thigh meat $(\mathrm{P}<0,05)$. Average fat contents of fresh raw chicken breast and thigh meat were 12,18 and 21,65\% (on dry weight basis), respectively.

It could be noticed that fresh raw chicken breast and thigh meat contained 3,93 and 3,72 \% ash (on dry weight basis), respectively.

Table 1. Chemical composition of fresh raw chicken meat (On dry weight basis)

Табл. 1. Химический состав мяса куриных грудок и бедер (в пересчёте на сухую массу)

\begin{tabular}{|c|c|c|}
\hline \multirow{2}{*}{ Indicators | Показатели } & \multicolumn{2}{|c|}{$\begin{array}{c}\text { Constituents (\%) | } \\
\text { Содержание (\%) в куриных: }\end{array}$} \\
\hline & Breast | грудках & Thigh | бедрах \\
\hline Moisture | Влага & 74,15 & 73,07 \\
\hline Total protein | Общий белок & 82,94 & 73,56 \\
\hline Total lipids | Общие липиды & 12,18 & 21,65 \\
\hline Total ash | Общая зола & 3,93 & 3,72 \\
\hline
\end{tabular}


тионина, изолейцина, лейцина, фенилаланина и лизина, в то время как мясо куриных бедер содержало большее количество аспарагиновой кислоты, глутаминовой кислоты, глицина, аланина, цистеина и тирозина. Натm [6] сообщил о сходных результатах. Так, им установлено, что на аминокислотный состав мяса бройлеров оказывают влияние район выращивания, порода, пол и возраст. Было обнаружено, что общие заменимые и незаменимые аминокислоты в мясе куриных грудок составляют 88,95 и 87,11; 50,49 и 51,37, а также 38,49 и 35,74 г/16 г N, соответственно. Однако мясо куриных грудок содержало больше незаменимых и меньше заменимых аминокислот по сравнению с мясом куриных бедер $(\mathrm{P}<0,05)$, что показано таблице 2.

Влияние времени термообработки на содержание аминокислот в мясе цыплят-бройлеров представлено в таблице 3. Из результатов в этой таблице ясно, что термообработка образцов мяса с куриных грудок или бедер приводила к некоторому снижению всех аминокислот. Образцы мяса куриных грудок или бедер, обработанных под давлением, сохраняли наибольшее содержание общих незаменимых, заменимых и общих аминокислот, а затем в порядке убывания количества аминокислот следовали следующие тепловые методы обработки: варка, обработка в микроволновой печи и поджаривание $(\mathrm{p}<0,05)$. Однако, существенные различия между способами термообработки в отношении содержания аминокислот в образцах мяса куриных грудок или бедер не были
The amino acid composition of fresh raw chicken breast and thigh meat is shown in Table 2. From the result illustrated in the table, it could be noticed that the fresh raw chicken breast and thigh meat contained the same individual amino acids with a slight differences $(\mathrm{P}>0,05)$ in their amounts. Similar results were found by Abd El- Wahed [2]. The results in the same table indicated that the fresh raw chicken breast meat contained greater amounts of serine, histidine, arginine, threonine, valine, methionine, isoleucine, leucine, phenylalanine and lysine, while fresh raw chicken thigh meat contained greater amounts of aspartic acid, glutamic acid, glycine, alanine, cysteine and tyrosine. Hamm [6] reported approximately the same results, and he found that the amino acid composition of raw broilers meat is influenced by area of production, strain, sex and age. The total non-essential and essential amino acids of fresh raw chicken breast and thigh meats were found to be 88,95 and 87,$11 ; 50,49$ and 51,37 as well as 38,49 and $35,74 \mathrm{~g} / 16 \mathrm{~g} \mathrm{~N}$, respectively. However, fresh raw chicken breast meat contained more total essential and less nonessential amino acids than fresh raw chicken thigh meat $(\mathrm{P}<0,05)$ as shown in the same Table 2.

The effect of cooking treatments on amino acids content of chicken meat is shown in Table 3. From the results in the table, it is clear that cooking of either fresh breast or thigh meat samples caused some decrease in all of their amino acids. The chicken breast and thigh meat samples cooked by pressure retained the highest percentages of total essential, non-essential and total amino acids, followed in a decreasing order by boiling, microwave and roasting methods

Table 2. Amino acids composition of fresh raw chicken meats $(\mathrm{g} / 16 \mathrm{~g} \mathrm{~N})$

Табл. 2. Аминокислотный состав мяса цыплят-бройлеров (г/16 г N)

\begin{tabular}{|c|c|c|}
\hline Amino acids | Аминокислоты & Breast | Грудки & Meat | Бедра \\
\hline \multicolumn{3}{|c|}{ Essential amino acids | незаменимые аминокислоты } \\
\hline Threonine | треонин & 3,09 & 2,80 \\
\hline Valine | валин & 5,87 & 4,62 \\
\hline Methionine | метионин & 2,92 & 2,50 \\
\hline Isoleucine | изолейцин & 5,01 & 4,79 \\
\hline Leucine | лейцин & 7,65 & 7,30 \\
\hline Tyrosine | тирозин & 2,48 & 2,55 \\
\hline Phenylalanine | фенилаланин & 3,59 & 3,44 \\
\hline Lysine | лизин & 7,85 & 7,74 \\
\hline Total essential amino acids | Всего незаменимых аминокислот & 38,46 & 35,74 \\
\hline \multicolumn{3}{|c|}{ Non-essential amino acids $\mid$ заменимые аминокислоты } \\
\hline Aspartic acid | аспарагиновая кислота & 8,95 & 9,32 \\
\hline Serine | серин & 3,20 & 3,14 \\
\hline Glutamic acid | глутаминовая кислота & 16,09 & 16,54 \\
\hline Glysine | глицин & 5,23 & 6,56 \\
\hline Alanine | аланин & 5,71 & 6,01 \\
\hline Histidine | гистидин & 3,87 & 2,75 \\
\hline Arginine | аргинин & 6,32 & 5,70 \\
\hline Cysteine | цистеин & 1,12 & 1,35 \\
\hline Total non- essential amino acids | Всего заменимьх аминокислот & 50,49 & 51,37 \\
\hline Total determined amino acids | Общие определенные аминокислоты & 88,95 & 87,11 \\
\hline
\end{tabular}


Table 3. Effect of cooking methods on amino acids composition of fresh raw chicken meat

Табл. 3. Влияние методов термообработки на аминокислотный состав мяса цыплят-бройлеров

\begin{tabular}{|c|c|c|c|c|c|c|c|c|c|c|}
\hline \multirow[b]{3}{*}{$\begin{array}{l}\text { Amino acids g/16g N | } \\
\text { Аминокислоты г/16r N }\end{array}$} & \multicolumn{5}{|c|}{ Breast | Грудки } & \multicolumn{5}{|c|}{ Thigh | Бедра } \\
\hline & \multicolumn{5}{|c|}{ Cooking methods | методы термообработки } & \multicolumn{5}{|c|}{ Cooking methods | методы термообработки } \\
\hline & 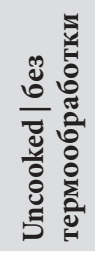 & 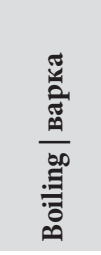 & 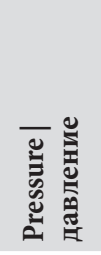 & 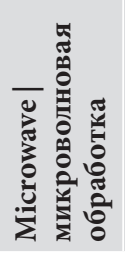 & 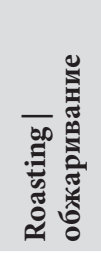 & 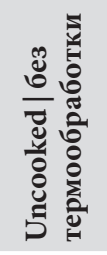 & 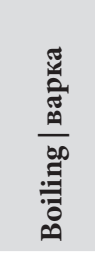 & 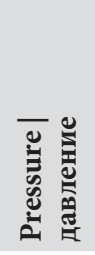 & 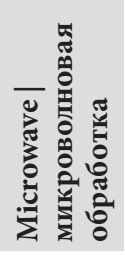 & 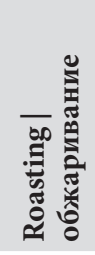 \\
\hline \multicolumn{11}{|c|}{ Essential amino acids | незаменимые аминокислоты } \\
\hline Threonine | треонин & 3,09 & 2,92 & 2,95 & 3,01 & 2,93 & 2,80 & 2,65 & 2,61 & 2,56 & 2,44 \\
\hline Valine | валин & 5,87 & 5,51 & 5,53 & 5,42 & 5,24 & 4,62 & 4,36 & 4,35 & 4,17 & 4,01 \\
\hline Methionine | метионин & 2,92 & 2,36 & 2,42 & 2,25 & 2,16 & 2,50 & 1,83 & 1,92 & 1,85 & 1,80 \\
\hline Isoleucine | изолейцин & 5,01 & 4,85 & 4,91 & 4,86 & 4,80 & 4,79 & 4,59 & 4,73 & 4,51 & 4,35 \\
\hline Leucine | лейцин & 7,65 & 6,93 & 6,95 & 7,02 & 6,95 & 7,30 & 6,41 & 6,52 & 6,36 & 6,21 \\
\hline Tyrosine | тирозин & 2,48 & 2,21 & 2,27 & 2,11 & 1,98 & 2,55 & 2,14 & 2,10 & 2,03 & 1,95 \\
\hline Phenylalanine | фенилаланин & 3,59 & 3,24 & 3,26 & 3,15 & 3,11 & 3,44 & 2,97 & 3,02 & 2,95 & 2,83 \\
\hline Lysine | лизин & 7,85 & 6,98 & 7,08 & 6,91 & 6,85 & 7,74 & 6,78 & 6,86 & 6,73 & 6,65 \\
\hline Total | Всего & 38,46 & 35,00 & 35,42 & 34,73 & 34,02 & 35,74 & 31,73 & 32,11 & 31,16 & 30,24 \\
\hline \multicolumn{11}{|c|}{ Non-essential amino acids | заменимые аминокислоты } \\
\hline Aspartic| аспарагиновая кислота & 8,95 & 8,72 & 8,83 & 8,64 & 8,55 & 9,32 & 8,91 & 8,96 & 8,75 & 8,59 \\
\hline Serine | серин & 3,20 & 3,06 & 3,11 & 3,02 & 2,98 & 3,14 & 2,93 & 2,97 & 2,96 & 2,87 \\
\hline glutamic | глутаминовая кислота & 16,09 & 15,81 & 15,90 & 15,81 & 15,74 & 16,54 & 16,16 & 16,21 & 15,95 & 15,83 \\
\hline Glysine | глицин & 5,23 & 4,96 & 5,02 & 4,93 & 4,85 & 6,56 & 6,25 & 6,32 & 6,18 & 6,12 \\
\hline Alanine | аланин & 5,71 & 5,41 & 5,46 & 5,30 & 5,26 & 5,01 & 5,76 & 5,81 & 5,72 & 5,61 \\
\hline Histidine | гистидин & 3,87 & 3,58 & 3,61 & 3,48 & 3,39 & 2,75 & 2,39 & 2,45 & 2,34 & 2,26 \\
\hline Arginine | аргинин & 6,32 & 5,90 & 5,39 & 5,81 & 5,77 & 5,70 & 5,18 & 5,23 & 5,10 & 4,94 \\
\hline Cysteine | цистеин & 1,12 & 0,96 & 0,98 & 0,93 & 0,87 & 1,35 & 1,17 & 1,10 & 1,14 & 0,97 \\
\hline $\begin{array}{l}\text { Total | Всего заменимых } \\
\text { аминокислот }\end{array}$ & 50,49 & 48,40 & 48,84 & 47,92 & 47,41 & 51,40 & 48,75 & 49,05 & 48,14 & 47,19 \\
\hline $\begin{array}{l}\text { Total determined amino acids | } \\
\text { Общие аминокислоты }\end{array}$ & 88,95 & 83,40 & 84,21 & 82,65 & 81,43 & 87,11 & 80,48 & 81,16 & 79,30 & 77,43 \\
\hline
\end{tabular}

обнаружены (Р > 0,05). В результате термообработки под давлением образцов мяса куриных грудок или бедер, было установлено, что общие аминокислоты снижались с 88,95 до 84,21 и с 87,11 до 81,16 г/16 г N, соответственно. При этом, они снижались с 88,95 до 81,43 и с 87,11 до 77,43 г/16 г N в образцах мяса грудок и бедер, обработанных поджариванием, соответственно. Исследования показали значительное снижение количества серосодержащих аминокислот, т.е., лейцина, тирозина, фенилаланина и лизина (как незаменимых аминокислот), а также серина, глицина, аланина, гистидина и аргинина (как заменимых аминокислот), в то же время было отмечено небольшое снижение в содержании других аминокислот после термообработки образцов мяса куриных грудок или бедер.

Таким образом, полученные результаты свидетельствуют, что термообработка образцов мяса куриных грудок или бедер приводила к снижению всех аминокислот. Снижение содержания аминокислот может быть связано как с потерей мясного сока, так и с денатурацией белков при термообработке.
$(\mathrm{P}<0,05)$. However, no significant differences were found among cooking methods on amino acids content $(\mathrm{P}>0,05)$ in either chicken breast or thigh meat samples. As a result of cooking of fresh breast and thigh meat samples by pressure, the total amino acids were found to decrease from 88,95 to 84,21 and from 87,11 to $81,16 \mathrm{~g} / 16 \mathrm{~g} \mathrm{~N}$, respectively. Meanwhile, they decreased from 88,95 to 81,43 and from 87,11 to $77,43 \mathrm{~g} / 16 \mathrm{gN}$, in the fresh breast and thigh meat samples cooked by roasting respectively. Marked amounts of sulpher containing amino acids, i.e. leucine, tyrosine, phenylalanine and lysine (as essential amino acids) as well as serine, glycine, alanine, histidine and arginine (as non-essential amino acids) were destroyed, while as slight decrease was noticed in all the other amino acid contents under cooking of chicken breast or thigh meat samples.

Furthermore, from the same obtained results it was clear that cooking of either fresh breast or thigh meat samples caused some decrease in all their amino acids. The reduction of amino acid content might be attributed to their loss with drippings separated during cooking as well as by the heat destruction. 


\section{Выводы}

Полученные результаты исследования могут быть резюмированы следующим образом:

- Не прошедшие кулинарную обработку образцы мяса куриной грудки имели более высокое содержание влаги, общего белка и золы, но более низкое содержание общих липидов;

- Не прошедшее кулинарную обработку мясо куриных грудок и бедер содержало одинаковое количество отдельных аминокислоты с небольшими изменениями в их количестве (Р $>0,05)$;

- Не прошедшее кулинарную обработку мясо куриной грудки содержит большее количество незаменимых и меньшее количество заменимых аминокислот, чем неприготовленное мясо куриного бедра $(\mathrm{P}<0,05)$;

- Образцы мяса куриной грудки и бедра, приготовленные под давлением, сохранили самое высокое количество незаменимых и заменимых аминокислот, а затем в порядке убывания следовали методы варки, обработки в микроволновой печи и поджаривания $(\mathrm{p}<0,05)$. Однако, существенные различия между изучаемыми образцами не были обнаружены в отношении содержания аминокислот $(\mathrm{P}>0,05)$.

БИБЛИОГРАФИЧЕСКИИ СПИСОК 1. Abd El-Baki, M.M.; Taha, R.A.; El-Zayet, F.M.M.; El-Dashlouty, A.A. and Fouda; Z.M.A. (1983). Influence of some pre-freezing treatments on the chemical and physical properties of chicken meat. Proc. $29^{\text {th }}$ Euro. Meeting of meat Res. Workers, Parma, 464. 2. Abd EL-wahed W.A.H. (1986). Effect of preparation and cooking methods on the constituents and characteristics of poultry meat. PH.D. Thesis, Faculty of Agric., Cairo univ.

3. Alfaia, C.M.G.A.; Alves, S.P.A.; Lopes,A.F.; Fernandes, M.J.E.; Costa,A.S.H.; Castro, M.L.F.; fonts, C.M.G.A.; Bessa, R.J.B.,\& Prates, J.A.M.(2010). Effect of household cooking methods on fatty acids conjugated isomers of linoleic acid and nutritional quality of beef intramuscular fat. Meat Scince, 84,769-777.

4. AOAC. International (2000). Official methods of analysis of AOAC International (17th ed.). Gaithersburg, MD, USA: Association of Analytical Communities.

5. Barr, A. J.; Goodnight, J.H.; Sall, J. P. and Helwig, J.T. (1976). "A Users Guide SAS 76" SAS Institute, Raleigh, N.C.; U.S.A.

6. Hamm, D.(1981). Amino acid composition of breast and thigh meat from broilers produced in four locations of United States. J.Food Sci., 46: 1122-1124.

7. Happich, M.L.; Whitmore, R.A.; Feairheller, S.; Taylar, M.M.; Swift, C.E.; Naghaski, J.; Booth A.N. and Alsmyer, R.H. (1975). Composition and protein efficiency ratio of partially defatted chopped beef and partially deffated beef fatty tissue and combinations with selected proteins. J. Food Sci., 40: 35-40.

8. Ibrahim, H.M. and Shams El-Din, M.H.A. (1989). Chemical composition and protein quality of chicken breast muscles. Grasas Y. Aceites, 40(2): 97-101.

9. Lea, C.H.; McForlane, J.J. and Parr,L.J. (1960). Chemical changes in meat due processing. J. Sci. Food Agric., 11: 690-695. 10. Macy, R.L. Jr.; Naurman, H.D. and Bailey, M.F. (1964). Soluble flavor odor precursors of meat. 1-Qualitative study of certain amino acids, carbohydrates, non-amino acid nitrogen compound and phosphoric acid esters of beef, Pork and lamb. J. Food Sci. 29: 136-148.

11. Mills, E.N.C. and Morgan M.R.A. (1990). Using biotechnology in the assessment of food quality. Food Technology Intr. Europ. Ed. Turner, A. Aterling publication International Ltd. P. 227.

12. Moawad, R.K. (1987). Effect of freezing and cooking on the chemical composition and biological quality of beef meat. MSc. Thesis, Faculty of Agric., Cairo Univ.

\section{Conclusion}

The obtained results from this study could be summarized as follows:

- Uncooked chicken breast meat samples had higher contents of moisture, total protein, and ash but lower contents of total lipids than uncooked thigh meat.

- Fresh raw chicken breast and thigh meat contained the same individual amino acids with a slight variation in their amounts $(\mathrm{P}>0,05)$

- Fresh raw chicken breast meat contained more total essential and less non-essential amino acids than fresh raw chicken thigh meat $(\mathrm{P}<0,05)$.

- The chicken breast and thigh meat samples cooked by pressure retained the highest amount of total essential, non-essential and total amino acids, if compared in a decreasing order with boiling, microwave and roasting methods, $(\mathrm{P}<0,05)$ but no significant difference among these cooking methods for amino acid contents were found $(\mathrm{P}>0,05)$.

\section{REFERENCES}

1. Abd El-Baki, M.M.; Taha, R.A.; El-Zayet, F.M.M.; El-Dashlouty, A.A. and Fouda; Z.M.A. (1983). Influence of some pre-freezing treatments on the chemical and physical properties of chicken meat. Proc. $29^{\text {th }}$ Euro. Meeting of meat Res. Workers, Parma, 464. 2. Abd EL-wahed W.A.H. (1986). Effect of preparation and cooking methods on the constituents and characteristics of poultry meat. PH.D. Thesis, Faculty of Agric., Cairo univ.

3. Alfaia, C.M.G.A.; Alves, S.P.A.; Lopes,A.F.; Fernandes, M.J.E.; Costa,A.S.H.; Castro, M.L.F.; fonts, C.M.G.A.; Bessa, R.J.B.,\& Prates, J.A.M.(2010). Effect of household cooking methods on fatty acids conjugated isomers of linoleic acid and nutritional quality of beef intramuscular fat. Meat Scince, 84,769-777.

4. AOAC. International (2000). Official methods of analysis of AOAC International (17th ed.). Gaithersburg, MD, USA: Association of Analytical Communities.

5. Barr, A. J.; Goodnight, J.H.; Sall, J. P. and Helwig, J.T. (1976). "A Users Guide SAS 76" SAS Institute, Raleigh, N.C.; U.S.A.

6. Hamm, D.(1981). Amino acid composition of breast and thigh meat from broilers produced in four locations of United States. J.Food Sci., 46: 1122-1124.

7. Happich, M.L.; Whitmore, R.A.; Feairheller, S.; Taylar, M.M.; Swift, C.E.; Naghaski, J.; Booth A.N. and Alsmyer, R.H. (1975). Composition and protein efficiency ratio of partially defatted chopped beef and partially deffated beef fatty tissue and combinations with selected proteins. J. Food Sci., 40: 35-40.

8. Ibrahim, H.M. and Shams El-Din, M.H.A. (1989). Chemical composition and protein quality of chicken breast muscles. Grasas Y. Aceites, 40(2): 97-101.

9. Lea, C.H.; McForlane, J.J. and Parr,L.J. (1960). Chemical changes in meat due processing. J. Sci. Food Agric., 11: 690-695. 10. Macy, R.L. Jr.; Naurman, H.D. and Bailey, M.F. (1964). Soluble flavor odor precursors of meat. 1-Qualitative study of certain amino acids, carbohydrates, non-amino acid nitrogen compound and phosphoric acid esters of beef, Pork and lamb. J. Food Sci. 29: 136-148.

11. Mills, E.N.C. and Morgan M.R.A. (1990). Using biotechnology in the assessment of food quality. Food Technology Intr. Europ. Ed. Turner, A. Aterling publication International Ltd. P. 227.

12. Moawad, R.K. (1987). Effect of freezing and cooking on the chemical composition and biological quality of beef meat. MSc. Thesis, Faculty of Agric., Cairo Univ. 
13. Mudgett, R.E. (1989). Microwave food processing. Food Technol., 43(1): 117-126.

14. Tornberg. E. (2005). Effect on heat on meat proteins- implications on structure and quality of meat products. Meat Science, 70, 493-508.

15. Usborn, W.R.; Kemp. J.D. and Moody, W.G. (1968). Relation of protein compound and free amino acids to both quality. J. Animal Sci., 27: 590-595.

16. Widner, K. and Eggum, B.O.(1966). Protein hydrolysis. A description of the method used at the department of animal physiology in Copenhagen. Acta Agriculture Scandinavia, 16: 115-118. C.F. The method of amino acid analyzer, Food and feed Lab., Agric. Research Center, Ministry of Agric., Giza, Egypt (1997).

17. Wilkinson, B.H.P.; Lee, E.,Purchas; R.W.\&Morel, P.C.H. (2014). The retention and recovery of amino acids from pork longissimus muscle following cooking to either 60 or $70^{\circ} \mathrm{C}$. Meat Science, 96, 361-365.

\section{СВЕДЕНИЯ ОБ АВТОРАХ}

Принадлежность к организации

Танаа Шехаб - доцент, департамент науки о пище, Агрономический факультет, Университет Аль-Фуарт

Сирия, Дейр-Аль-Зор, ул. Халид Бин Аль Валид

Тел.: +963-944-393-708

E-mail: Thanayasser@Hotmail.com

Критерии авторства

Ответственность за работу и предоставленные сведения несет автор и несет ответственность за плагиат.

Конфликт интересов

Автор заявляет об отсутствии конфликта интересов.

Поступила 05.10.2016
13. Mudgett, R.E. (1989). Microwave food processing. Food Technol., 43(1): 117-126.

14. Tornberg. E. (2005). Effect on heat on meat proteins- implications on structure and quality of meat products. Meat Science, 70, 493-508.

15. Usborn, W.R.; Kemp. J.D. and Moody, W.G. (1968). Relation of protein compound and free amino acids to both quality. J. Animal Sci., 27: 590-595.

16. Widner, K. and Eggum, B.0.(1966). Protein hydrolysis. A description of the method used at the department of animal physiology in Copenhagen. Acta Agriculture Scandinavia, 16: 115-118. C.F. The method of amino acid analyzer, Food and feed Lab., Agric. Research Center, Ministry of Agric., Giza, Egypt (1997).

17. Wilkinson, B.H.P.; Lee, E., Purchas; R.W.\&Morel, P.C.H. (2014). The retention and recovery of amino acids from pork longissimus muscle following cooking to either 60 or $70^{\circ} \mathrm{C}$. Meat Science, 96, 361-365.

\section{AUTOR INFORMATION}

Affiliation

Thanaa Shehab - associate prof., Foods Science Department, Faculty of Agriculture, Al-Fuart University

Syria, Deir Ezzor, Khalid Bin Al Waleed str.

Tel.: +963-944-393-708

E-mail: Thanayasser@Hotmail.com

Contribution

Author have responsibility for the information in manuscript and are equally responsible for plagiarism.

$$
\text { Conflict of interest }
$$

The author declare no conflict of interest.

Received 05.10.2016 